\title{
Feldspar-banana peel composite adsorbent for efficient crude oil removal from solution
}

\author{
Folasegun A. Dawodu ${ }^{1} \cdot$ Chika J. Abonyi ${ }^{1} \cdot$ Kovo G. Akpomie ${ }^{2,3}$
}

Received: 12 September 2020 / Accepted: 26 November 2020 / Published online: 4 December 2020

(c) The Author(s) 2020

\begin{abstract}
The problem of oil spill pollution associated with the transport of crude oil and its products across the globe is of serious concern. The sorption technique has proved to be promising for oil spill treatment but is limited by the hydrophilic nature of most natural organic sorbents. The combo of natural organic and inorganic sorbents have been found to enhance the hydrophobicity for oil sorption. Therefore this study was aimed at the preparation of a novel feldspar-banana peel biochar composite (FBPC) with enhanced hydrophobicity for the sorption of crude oil. The prepared sorbent was characterised by the scanning electron microscopy (SEM) and X-ray diffraction (XRD) techniques, while the crude oil was characterised using standard methods. Batch sorption was used to determine the effect of contact time $(30-150 \mathrm{~min})$, temperature $\left(25-100{ }^{\circ} \mathrm{C}\right)$, $\mathrm{pH}(2.0-10.0)$, oil concentration $(4.0-12.0 \mathrm{~g} / \mathrm{L})$ and sorbent dosage $(0.1-0.5 \mathrm{~g})$ on sorption. SEM analysis of FBPC revealed a porous structure, while XRD confirmed the crystalline phases of feldspar. The crude oil samples had pH (6.40-6.60), density $\left(0.96000 .962 \mathrm{~g} / \mathrm{cm}^{3}\right)$, kinematic viscosity $(24.0-27.6 \mathrm{cSt})$ and API gravity $\left(24.25-24.51^{\circ}\right)$. The Langmuir model with $R^{2}>0.7781$ presented the best fit than the Temkin and Freundlich model in the isotherm analysis, while the pseudosecond-order model with $R^{2}>0.9711$ was applicable in the kinetics of sorption. The thermodynamic analysis revealed a decrease in randomness at the crude oil-FBPC interface. The prepared FBPC was found to be an efficient inorganic-organic composite sorbent with enhanced hydrophobicity for the sorption of crude oil.
\end{abstract}

Keywords Biochar $\cdot$ Sorption $\cdot$ Feldspar $\cdot$ Banana peel $\cdot$ Composite $\cdot$ Crude oil

\section{Introduction}

Pollution has been a worrying experience to humanity for the past few decades, since the advent of technology and man's quest for industrialisation. Oil pollution in the environment has been a major source of concern for the people living in crude oil-rich areas (Ohanmu and Bako 2017). Oil pollution occurs during exploration, extraction, refining, shipping and transportation, storage, or in form of leakages in the pipelines. Onshore oil spillage is very phytotoxic to plant and injurious to animals (FEPA 1991). Gas flaring during the

Chika J. Abonyi

jcj.abonyi4niz@yahoo.com

1 Department of Chemistry (Industrial), University of Ibadan, Ibadan, Nigeria

2 Department of Pure and Industrial Chemistry, University of Nigeria, Nsukka, Nigeria

3 Department of Chemistry, University of the Free State, Bloemfontein, South Africa exploration of crude oil does not only cause global warming through the excess release of greenhouse gases $\left(\mathrm{CO}_{2}, \mathrm{NO}_{2}\right.$, $\mathrm{SO}_{2}$ ) to the atmosphere but as well causes ocean acidification (UNEP/GRID 2011). The presence of heteroatoms (sulphur, nitrogen, metals, etc.) in crude oil is also a threat to the environment. Sulphur-containing compounds burn to release sulphur, which forms sulphuric acid and causes acid rain. Nitrogen and trace metals are potential catalyst poisons while aromatic compounds like benzene and benzene-unit compounds are carcinogenic (Topsoe et al. 1996). However, besides the environmental impact of the heteroatoms, oil spillage has remained the most common as well as devastating contaminants of the environment. It had not only contaminated the potable drinking water but also denatured the marine environment and jeopardised the aquatic lives.

Though the benefits of crude oil to humanity are enormous, crude oil-polluted water has been a major source of concern as it poses a serious threat to aquatic life, plants, and humans (Ani et al. 2020). This is due to their high toxicity, non-biodegradability, accumulation in the food

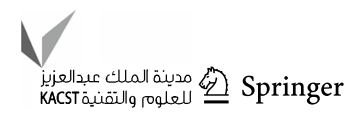


chain, and drastic reduction and degradation of marine oxygen (Singh et al. 2011). Hence, the determination and subsequent removal of crude oil and other pollutants from water bodies are vital in maintaining environmental quality and has recently become a dominant topic for researchers. Conventional techniques have been employed for the removal of crude oil from waters regardless of being physical, chemical, or biological. These include evaporation, coagulation, floatation, filtration, solvent extraction, chemical precipitation, electrochemical treatment, degradation, ion exchange, oxidation/reduction, reverse osmosis, membrane separation, and activated carbon adsorption (Eze et al. 2019; Akpomie et al. 2019; Dawodu et al. 2018).

However, most of these existing processes have the disadvantages of high cost, low removal efficiency, secondary contamination, difficulty to apply, and high energy requirement (Liang et al. 2010). Adsorption as a technique for the treatment of crude oil-polluted water is highly efficient, simple, and feasible, but due to the high cost involved in utilising activated carbon, several low-cost adsorbents have been utilised such as biomass materials, clays, microorganisms, and ash (Li et al. 2011; Saleh and Gupta 2012). Particularly, biomass materials that have been extensively used include yam peels, wheat straw, sawdust, rice residues, corncob, coconut husk, kenaf, kapok fibres, cotton, wool, and wood (Sathasivam and Mas-Haris 2010; Ali et al. 2012). The advantages of these materials include being cheaper, biodegradability, and non-toxic (Akpomie and Conradie 2020).

Feldspar is a tectosilicate mineral, $\mathrm{NaAlSi}_{3} \mathrm{O}_{8}$ or $\mathrm{CaAl}_{2} \mathrm{Si}_{2} \mathrm{O}_{8}$ and can be used as a potential adsorbent due to its surface area, pore structure, and morphology. Modification of this material through chemical treatments like alkaline, acid, and organics is believed to further increase the adsorption capacity as it would enhance the active sites by presenting heterogeneous surfaces. However, the application of these chemicals is costly, quite complex, and requires skilled personnel, therefore limiting its widespread use. Hence, the need to develop cheaper alternative means of modification having adsorption potentials comparable to or better than the chemically modified forms. Sequel to this, it is, therefore, possible that the introduction of banana peels to feldspar would present a heterogeneous surface with better adsorption potential and hydrophobicity than the chemically treated forms and also have the advantage of a lower cost.

Precisely, this present study investigated the use of feldspar-banana peel (Musa acuminata) biochar composite as a cheap and novel adsorbent for the removal of crude oil from aqueous solution. The effects of contact time, adsorbent dosage, crude concentration, $\mathrm{pH}$, and temperature on the sorption process were studied. In addition, equilibrium isotherm, kinetic and thermodynamic parameters were determined.

\section{Materials and method}

\section{Sample preparation}

The powdered feldspar was obtained from the Federal Institute of Industrial Research Oshodi (FIIRO), Lagos, Nigeria while the banana peels were collected from Oje Market, Oje, Ibadan, Nigeria. Similarly, the crude oil samples, Estuary and Yokri, were obtained from separate oil wells of the Shell Petroleum Development Company (SPDC), Delta State, Nigeria, through the Nigerian National Petroleum Corporation (NNPC) Division, Portharcourt, Nigeria. The Estuary crude oil was collected from Estuary Oilfield Well-27S extracted on December 10, 2018, while Yokri crude oil was gotten from Yokri Oilfield Well-127 T extracted on February 1, 2019. These samples were specifically collected from these oil wells as a suitable representative of crude oil present in Nigeria.

The raw feldspar was first sieved, using 100- $\mu \mathrm{m}$ mesh size, to remove larger particles and unwanted substances. It was dispersed in excess distilled water in a pre-treated plastic container, stirred to ensure uniform dissolution, and then filtered. The filtrate was kept for $24 \mathrm{~h}$ to settle, after which excess water was decanted, and the residue was treated with $30 \%$ conc. $\mathrm{H}_{2} \mathrm{O}_{2}$ solution by gradual addition and stirring to oxidise all traces of organic present and kept undisturbed for $24 \mathrm{~h}$. The supernatant was decanted and the feldspar was washed with distilled water to neutral $\mathrm{pH}$, dried in an oven at $105{ }^{\circ} \mathrm{C}$ for $24 \mathrm{~h}$, and cooled in a desiccator. The dried feldspar was ground using mortar and pestle, and then passed through a $100-\mu \mathrm{m}$ mesh sieve and stored in an air-tight container.

The banana peels were cut into pieces, washed several times with distilled water to remove dust/dirt followed by sun-drying for 1 week. The sun-dried banana peels were crushed to increase the surface area, sieved through 100 $\mu \mathrm{m}$ mesh, oven-dried at $105^{\circ} \mathrm{C}$ for $24 \mathrm{~h}$, and then heated in a muffle furnace at $300{ }^{\circ} \mathrm{C}$ for $6 \mathrm{~h}$, since lower temperature produces more char (Winsley 2007), to give activated charcoal (biochar). The prepared biochar was cooled, washed with distilled water until it was clean, oven-dried at $105{ }^{\circ} \mathrm{C}$ for $3 \mathrm{~h}$, sieved using $100-\mu \mathrm{m}$ mesh, and stored in an air-tight container.

A total of $100 \mathrm{~g}$ each of purified feldspar and prepared banana peel powder (1:1) was mixed in 500-mL flask with $200 \mathrm{~mL} 0.1 \mathrm{M} \mathrm{NaOH}$, dried in an oven at $105^{\circ} \mathrm{C}$ for $24 \mathrm{~h}$, and then charred in a muffle furnace at $300{ }^{\circ} \mathrm{C}$ for $6 \mathrm{~h}$, after which the furnace was cooled, and the black hybrid removed from the furnace. The charred hybrid was washed with distilled water to remove ash, drained, and oven-dried at $105{ }^{\circ} \mathrm{C}$ for $24 \mathrm{~h}$, designated as FBPC, and kept in an airtight container for use. 


\section{Sorbent characterisation}

The scanning electron microscope (SEM) analysis was carried out to ascertain the surface topography, pore structure, morphology, structural changes, and composition of FBPC. The prepared FBPC was first placed in the sample stud and then the stud placed at the sample compartment where the SEM (VEG A3 TESCAN) was run to determine the characteristic pore structures. X-ray Diffractometry (XRD) was used to investigate the atomic arrangement, phase composition as well as crystalline phases of FBPC. The powdered FBPC was first pelletised, taken in an aluminium alloy grid on a flat glass plate covered with a paper, and then placed in the sample compartment where the sample was then run in Rigaku D/max-IIIC X-ray diffractometer to determine the crystalline phases of the FBPC. The $\mathrm{pH}$ of FBPC was determined at $25^{\circ} \mathrm{C} .20 \mathrm{~mL}$ of distilled water was added into $1.0 \mathrm{~g}$ of adsorbent in an amber glass bottle, shaken, allowed to stand for $24 \mathrm{~h}$, and then filtered. The $\mathrm{pH}$ of the supernatant was taken using a calibrated (BOSCH PHS Microprocessor) $\mathrm{pH}$ meter.

\section{Crude oil characterisation}

The physicochemical characterisations of the crude oil samples were performed to determine properties like density, $\mathrm{pH}$, viscosity (kinematic and dynamic), API gravity, moisture, and ash contents (Appenteng et al. 2013; Nwadinigwe and Alumona 2014; Ofodile et al. 2018; Rodrigues et al. 2018). For each parameter, the experiment was conducted trice, and the mean value determined for quality assurance. Briefly, $50 \mathrm{~mL}$ capacity clean dry empty density bottle was first weighed at $25^{\circ} \mathrm{C}$, filled with crude oil to the brim and then carefully corked to expel trapped air. The bottle with the sample was then weighed and the density was determined according to the formula:

$\rho=\frac{W_{2}-W_{1}}{V}$

where $W_{1}$ is the weight of the empty bottle, $W_{2}$ is the weight of the bottle with sample and $V$ is the volume of the density bottle.

The $\mathrm{pH}$ determination was carried out as follows; exactly $30 \mathrm{~mL}$ of crude oil sample was measure into a clean dry beaker and the $\mathrm{pH}$ electrode was dipped into the sample at $25{ }^{\circ} \mathrm{C}$. The sample was stirred for $30 \mathrm{~s}$ and then allowed to stand. The $\mathrm{pH}$ was taken at the point of stability of the $\mathrm{pH}$ reading on the $\mathrm{pH}$ meter.

The viscosity of the crude oil samples was determined using Ostwald viscometer. The crude oil sample was carefully taken, with a syringe, into arm I of the U-shaped tube at $25{ }^{\circ} \mathrm{C}$, till it reaches mark II. It was subsequently drawn, by suction, into arm II (capillary arm) and allowed to flow down through the capillary arm into the lower bulb A. Two marks: one above and one below the upper bulb B, indicate a known volume. The time for the meniscus of the crude oil to pass between these marks is taken and is related to kinematic viscosity according to the formula:

$K_{\mathrm{v}}=V_{\mathrm{f}} x R_{\mathrm{t}}$

$D_{\mathrm{v}}=K_{\mathrm{v}} x \rho$

where $K_{v}$ is kinematic viscosity; $D_{v}$ is dynamic viscosity; $V_{f}$ is viscometer factor; $R_{t}$ is residence time; $\rho$ is density.

The API gravity was calculated by determining from the specific gravity (S.G) of the crude oil sample using this equation.

APIgravity $=\frac{141.5}{S . G\left(60^{\circ} \mathrm{F}\right)}-131.5$

In the determination of moisture content, $5.0 \mathrm{~g}$ of the crude oil sample was taken, using a dropper, into a glass fibre paper, placed in a moisture analyser machine (ANDMX-50 Moisture Analyser) at $105^{\circ} \mathrm{C}$. Thereafter, the moisture reading was taken in percentage after $3 \mathrm{~h}$.

For the determination of the ash content, a clean dry empty crucible was first weighed, filled with $2.0 \mathrm{~g}$ of crude oil, and weighed again. The crucible with the sample was gently heated to burn at a uniform and moderate rate leaving only carbonaceous residue, then transferred into a muffle furnace, heated at $500{ }^{\circ} \mathrm{C}$ for $30 \mathrm{~min}$, and cooled. The amount of ash was determined using the formula.

Ash mass $\%=\frac{W_{3}-W_{1}}{W_{2}} \mathrm{X} 100$

where $W_{1}$ is the weight of empty crucible, $W_{2}$ is the weight of crude oil in the crucible and $W_{3}$ is the weight of crucible containing the ash after heating at $500{ }^{\circ} \mathrm{C}$.

\section{Batch sorption}

The batch sorption method was used in this study. A definite concentration of $7.50 \mathrm{~g} / \mathrm{l}$ of crude oil solution was prepared by adding $7.50 \mathrm{~g}$ of crude oil in $1.0 \mathrm{~L}$ of distilled water. The $\mathrm{pH}$ of the mixtures was adjusted, using a $\mathrm{pH}$ meter, to the required value with $0.1 \mathrm{M} \mathrm{HCl}$ or $0.1 \mathrm{M} \mathrm{NaOH}$. Several parameters affect the uptake of adsorbate by the adsorbent. Thus the effect of contact time (30-150 min), adsorbent dosage (0.1-0.5 g), crude oil concentration (4.0-12.0 g/l), $\mathrm{pH}(2.0-10.0)$, temperature $\left(25-100^{\circ} \mathrm{C}\right)$ were studied. The adsorption experiments were performed by equilibrating $0.2 \mathrm{~g}$ of FBPC with $25.0 \mathrm{ml}$ of prepared crude oil solution in a stoppered conical flask, at room temperature. The flask 
and its contents were agitated in a temperature-controlled mechanical orbital shaker at $200 \mathrm{rpm}$ for temperature regulation. In each case, one parameter was varied, while others are kept constant at optimum conditions. At the end of the given contact time, in which equilibrium has been attained, the mixtures were centrifuged at $5000 \mathrm{rpm}$, to separate the adsorbent from the oil-water mixture solution. The amount of crude oil removed was determined gravimetrically (Akpomie et al. 2018). Each experiment was conducted in triplicate and the mean value computed to obtain quality assurance. The amounts of crude oil adsorbed per unit mass of adsorbent at equilibrium, $q_{e}(\mathrm{mg} / \mathrm{g})$, or at time $\mathrm{t}, q_{t}$ $(\mathrm{mg} / \mathrm{g})$, and percent uptake of crude oil by the composite was expressed and calculated according to the following expressions:

$\%$ Removal $=\left(\frac{C_{0}-C_{e}}{C_{0}}\right) \times 100$

$q_{\mathrm{e}}=\left(\frac{C_{0}-C_{e}}{m}\right) v$

$q_{t}=\left(\frac{C_{0}-C_{t}}{\mathrm{~m}}\right) v$

where $\mathrm{m}(\mathrm{g})$ is the sorbent mass, $\mathrm{V}(\mathrm{L})$ is the volume of oil-water mixture used, while $\mathrm{Ce}$ and $\mathrm{Co}$ in $\mathrm{mg} / \mathrm{L}$ is the equilibrium and initial crude oil concentrations respectively.

\section{Results and discussion}

\section{Sorbent and crude oil characterisation}

The morphology and pore structure of FBPC were displayed in the SEM image (Fig. 1). The surface roughness of the FBPC micrograph revealed the availability of large pores of the sorbent, which is desirable in enhancing sorption of the crude oil. The X-ray diffractogram (Fig. 2) of FBPC revealed the crystalline phases as potassium feldspar $\mathrm{K}-\mathrm{Al}_{4}\left[\mathrm{Si}_{4} \mathrm{O}_{10}\right](\mathrm{OH})$, ilmenite $\mathrm{TiO}_{2}$, pyrite $\mathrm{FeS}_{2}$, and limestone $\mathrm{CaCO}_{3}$. Various peak areas also, were shown by it. $\mathrm{K}$ is found between 12.5-62.0, Ti at 25.1-76.0, while $\mathrm{Fe}$ and $\mathrm{C}$ are found at 27.5-57.0 and 30.0-49.0 respectively, all at $2 \theta$ angle. The $\mathrm{pH}$ result of FBPC obtained as 8.40 was found to be slightly alkaline. The results of XRD and $\mathrm{pH}$ are consistent with the composition of feldspar; $\mathrm{SiO}_{2}, \mathrm{Al}_{2} \mathrm{O}_{3}, \mathrm{Na} / \mathrm{K}_{2} \mathrm{O}$, and $\mathrm{CaO}$, indicating that feldspar is a principal component of the composite.

The physicochemical properties of the crude oils are presented in Table 1 . The density of crude oil is an indication of the composition of crude oil as well as the ease with
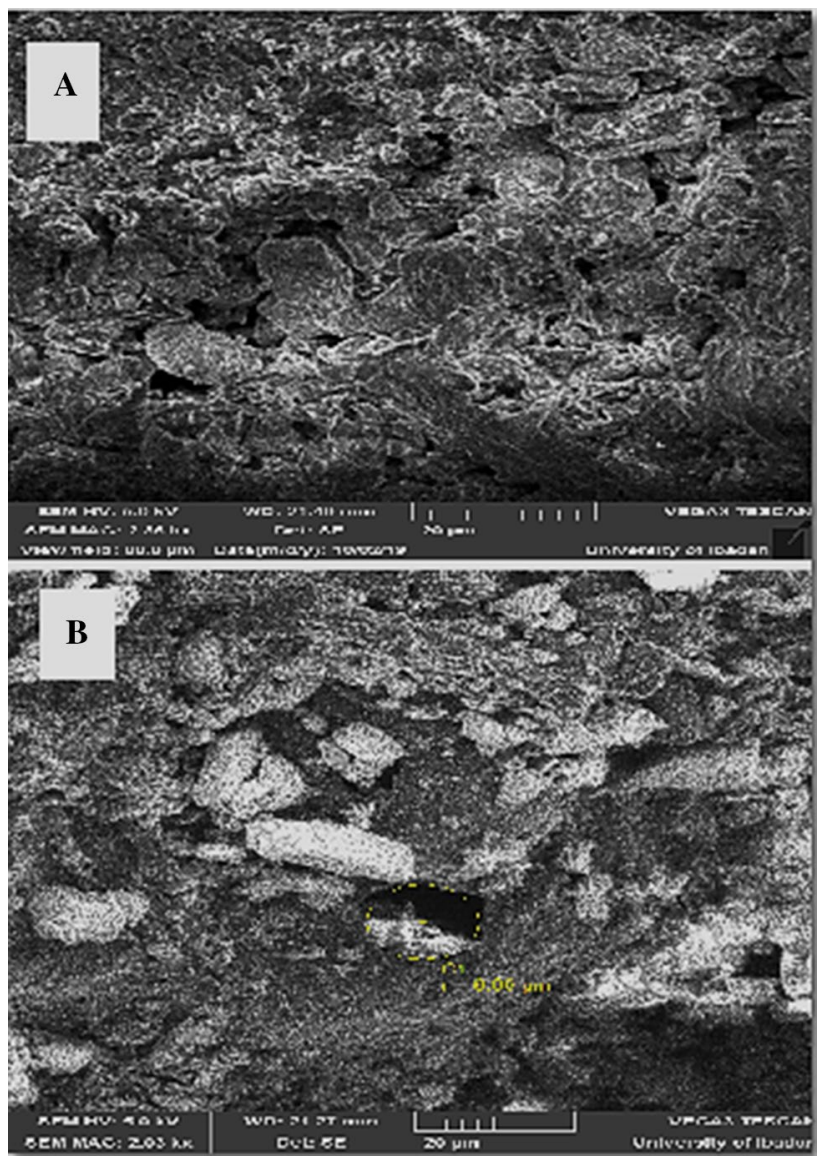

Fig. 1 SEM micrograph of FBPC at magnifications a 1000X and b $2000 \mathrm{X}$

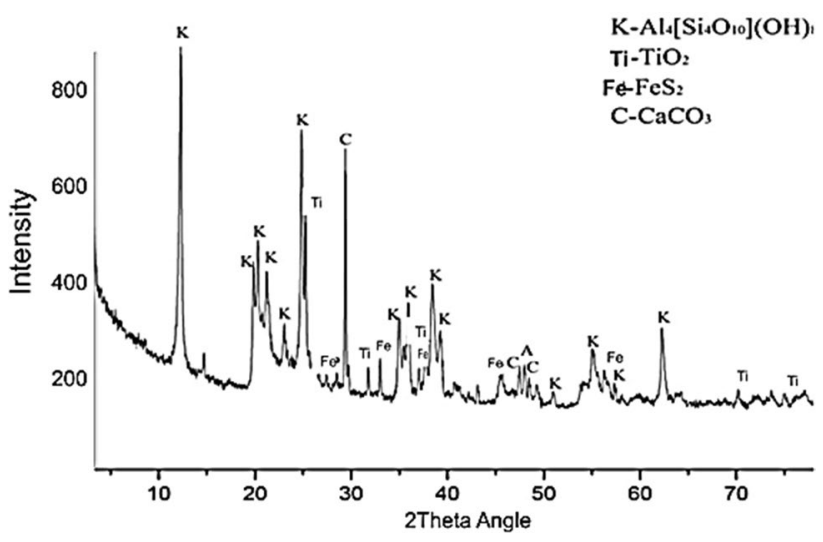

Fig. 2 XRD diffraction of FBPC

which it can be processed. From the results, Estuary crude oil is denser and hence has lower API gravity as compared to Yokri crude oil. This is because API gravity and density have a reciprocal relationship. The $\mathrm{pH}$ of a crude oil enables us to determine how acidic or alkaline a crude oil sample might be. It gives an insight into the presence of salts and 
Table 1 Physicochemical characterisation of the crude oils

\begin{tabular}{llll}
\hline Parameter & Temp. $\left({ }^{\circ} \mathrm{C}\right)$ & Estuary & Yokri \\
\hline Density $\left(\mathrm{g} / \mathrm{cm}^{3}\right)$ & 25 & 0.962 & 0.960 \\
$\mathrm{pH}$ & 25 & 6.40 & 6.60 \\
Kin. Viscosity $(\mathrm{cSt})$ & 25 & 27.60 & 24.00 \\
Dyn. Viscosity $(\mathrm{cP})$ & 25 & 26.56 & 23.04 \\
API Gravity $\left({ }^{\circ}\right)$ & 25 & 24.25 & 24.51 \\
Moisture Content $(\mathrm{ppm})$ & 105 & $3.658 \times 10^{5}$ & $4.387 \times 10^{5}$ \\
Ash Content $(\%)$ & 500 & 0.225 & 0.315 \\
\hline
\end{tabular}

other dissolved substances, which can roughly reveal the quality of the crude oil sample. In this study, the $\mathrm{pH}$ of both crude oils is slightly acidic with Yokri crude oil tending more to neutrality (6.60) when compared to Estuary crude oil (6.40). This result was expected and may be due to the presence of dissolved salts in the oil. Viscosity reflects the way molecules interact to resists motion and it is a vital fluid's properties influencing the ability of the fluid to minimise friction while flowing. Crude oil viscosity is an important physical property that controls and influences the flow of oil through porous media and pipes. Its measurement also helps in the pump design and gives a rough idea about the different fraction of crude oil (Ghulam et al. 2013). The lower the viscosity the lighter the crude oil fractions and vice versa. The results of Table 1 revealed that Estuary crude oil is more viscous than Yokri and thus has lower API gravity and more heavy fractions. API gravity is one of the properties that have the greatest influence on the value of crude oil. It is employed in the petroleum industry to determine how light or heavy a crude oil sample is compared to water and has a reciprocal relationship with specific gravity. According to Ghulam et al. (2013) and Ofodile et al. (2018), the higher the API gravity, the lighter the nature of the crude oil and vice versa. Consequently, lighter crude oil has API gravity higher than $31.1^{\circ}$, medium crude oil; $22.3-31.1^{\circ}$ and heavy crude oil, less than $20^{\circ}$. In this study (Table 1), Estuary and Yokri crude oils are of medium crude in nature with Yokri crude slightly tending towards paraffinic compared to Estuary. This agrees with the research by Odebunmi et al. (2002) on Bonny terminal crude oil in Bayelsa State, Nigeria, which showed that it was a medium crude.

The determination of the amount of moisture in crude oil has always been important to have a net dry oil of good pricing as well as high quality devoid of moisture, which will pose little or no corrosion threats during refining. From the results, Yokri crude oil contains more moisture than Estuary crude oil. Ash content of crude oil is a measure of the amount of inorganic non-combustible material it contains. These materials, which may be present naturally or formed during refining, storage, or distribution are obtained after the combustion of crude oil in the air at a specific high

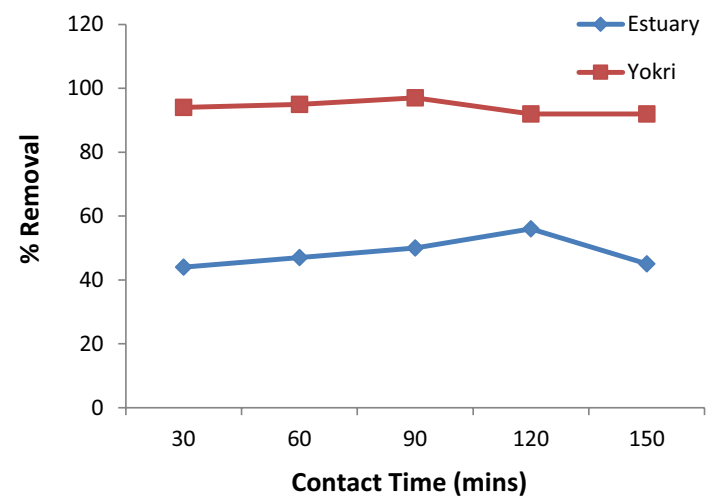

Fig. 3 Effect of contact time on the sorption of crude oils onto FBPC

temperature usually $500{ }^{\circ} \mathrm{C}$. Crude oil containing more than $0.05 \%$ ash content is considered high ash oil whereas those having less than $0.02 \%$ are regarded as low ash oil (Yasir 2015). The results of Table 1 revealed that both crude oils are high ash oils with Yokri having a higher value.

\section{Effect of contact time}

To investigate the kinetics of sorption of crude oils from solution onto FBPC, the effect of contact time was studied at a time interval of 30-150 min as shown in Fig. 3. For Estuary crude oil solution, there was an increase in percentage removal as time increased from $44 \%$ at $30 \mathrm{~min}$ to $56 \%$ at $120 \mathrm{~min}$ where the maximum removal was attained after which the percentage removal decreased to $45 \%$ at $150 \mathrm{~min}$. This is due to the desorption of oil into the solution. Similarly, for Yokri crude oil solution, there was an increase in percentage removal as the time increased from $94 \%$ at $30 \mathrm{~min}$ to $97 \%$ at $90 \mathrm{~min}$ where the maximum removal was attained after which the percentage removal decreased to $92 \%$ at $120 \mathrm{~min}$. The rapid uptake of crude oil by the FBPC at the initial stage is due to the presence of abundant active sites on the surface of FBPC, which gets used up with time, attaining saturation (Meitei and Prasad 2013). However, at a longer contact time, the whole available site on the FBPC would have been occupied as adsorption becomes more difficult and no crude oil can be adsorbed, thus leading to desorption.

\section{Effect of sorbent dosage}

It is important to determine the influence of adsorbent dosage on the adsorption of crude oil from solution as variation in the dosage affects the available site for adsorption. In this regard, the result of the adsorption of both Estuary and Yokri crude oils from solutions as a function of FBPC dosage was studied at $25^{\circ} \mathrm{C}$ as shown in Fig. 4. The percentage removal of Estuary crude oil increased gradually from $34 \%$ at $0.1 \mathrm{~g}$

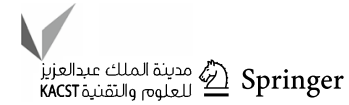




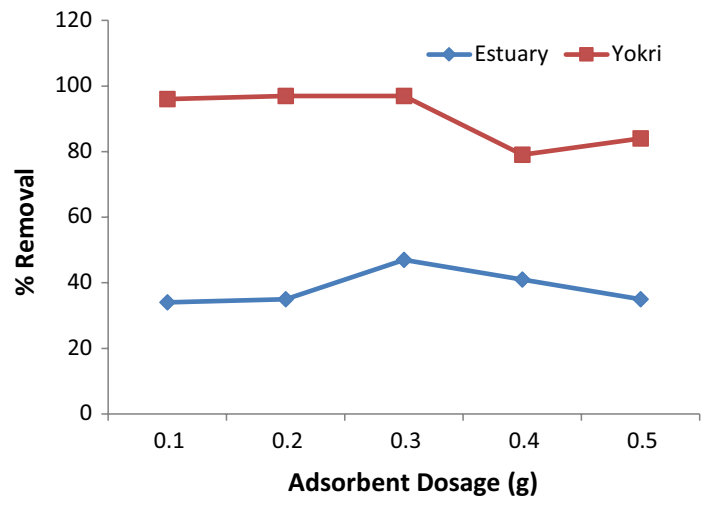

Fig. 4 Effect of adsorbent dosage on the sorption of crude oils onto FBPC

to $35 \%$ at $0.2 \mathrm{~g}$, with the highest removal of $47 \%$ attained at $0.3 \mathrm{~g}$ after which the percentage removal decreased due to the desorption process. Also, the percentage removal of Yokri crude oil increased gradually from $96 \%$ at $0.1 \mathrm{~g}$ to $97 \%$ at $0.2 \mathrm{~g}$, attaining maximum removal of $97 \%$ at $0.3 \mathrm{~g}$, and thereafter the percentage removal decreased. The initial increase in adsorption with dosage is due to an increase in the active sites for crude oil removal (Chukwuemeka-Okorie et al. 2018).

\section{Effect of crude oil concentration}

In adsorption studies, the effect of initial adsorbate concentration is an important factor to be determined. This is because the adsorption intensity of adsorbent is a function of the initial concentration of adsorbate. In other words, the rate and uptake of the adsorbate by the sorbent is dependent upon its concentration in solution. In this study, the effect of Estuary and Yokri crude oil concentrations on adsorption by FBPC is presented in Fig. 5. The results revealed that an increase in the initial concentration of the Estuary crude oil solution increased the percentage removal of crude oil. As the initial concentration

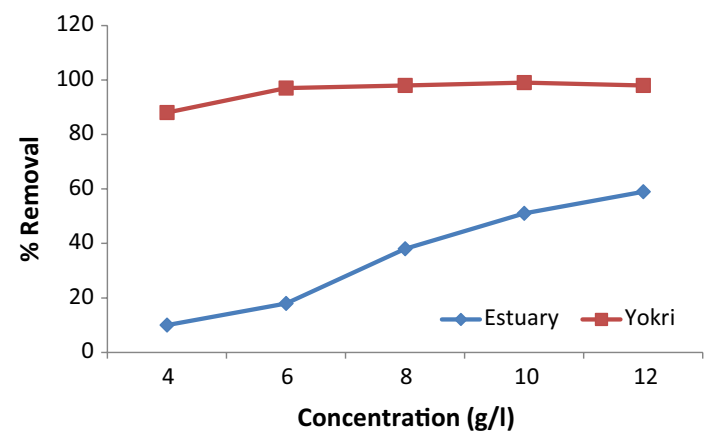

Fig. 5 Effect of concentration on sorption of crude oils onto FBPC increases, the percentage removal increased from $10 \%$ at $4 \mathrm{~g} / \mathrm{l}$ to $59 \%$ at $12 \mathrm{~g} / \mathrm{l}$ after which there was a decrease in the percentage removal. Similarly, there was an increase in percentage removal as the initial concentration of Yokri crude oil was increased from $88 \%$ at $4 \mathrm{~g} / \mathrm{l}$ to $99 \%$ at $10 \mathrm{~g} / \mathrm{l}$, thereafter there was a decrease in percentage removal. The increase in adsorption with an increase in concentration may be attributed to a higher concentration gradient which acts as a driving force to overcome the resistance of mass transfer of the crude oil between the solid and the aqueous phase (Liang et al. 2010). On the contrary, a decrease in percentage removal with an increase in initial concentration was observed. This is because each type of adsorbent has a limited number of active sites that become saturated at certain concentrations (Meitei and Prasad 2013).

\section{Effect of solution pH}

Adjustment of solution $\mathrm{pH}$ alters the binding sites of sorbent, which in turn affects the sorption. Fig. 6 shows the effect of solution $\mathrm{pH}$ on the adsorption of Estuary and Yokri crude oils by FBPC. An increase in $\mathrm{pH}$ of the Estuary crude oil solution resulted in a decrease in the percentage removal of the crude oil. As the $\mathrm{pH}$ increased, the percentage removal sharply decreased from $97 \%$ at $\mathrm{pH} 2$ to $38 \%$ at $\mathrm{pH} 4$ and continues till $35 \%$ at $\mathrm{pH} 8$ after which a slight increment was observed. The slight increment observed from $35 \%$ at $\mathrm{pH} 8$ to $39 \%$ at $\mathrm{pH} 10$ may be due to the rapid attainment of the equilibrium between the amount of the oil adsorbed and the amount of the oil remaining in the solution. In the same vein, for Yokri crude oil, an increase in the $\mathrm{pH}$ of the crude oil solution resulted in a decrease in percentage removal of the crude oil from $99 \%$ at $\mathrm{pH} 2$ to $93 \%$ at $\mathrm{pH} 10$. These results indicate that lower $\mathrm{pH}$ was more favourable for the crude oil sorption on FBPC.

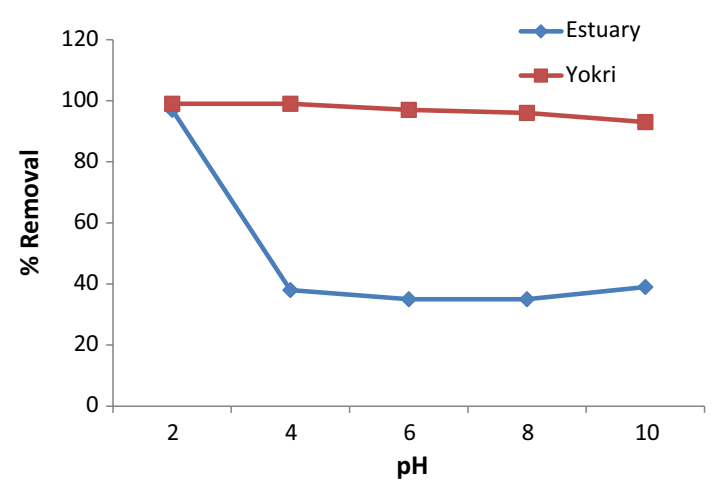

Fig. 6 Effect of $\mathrm{pH}$ on the sorption of crude oils onto FBPC 


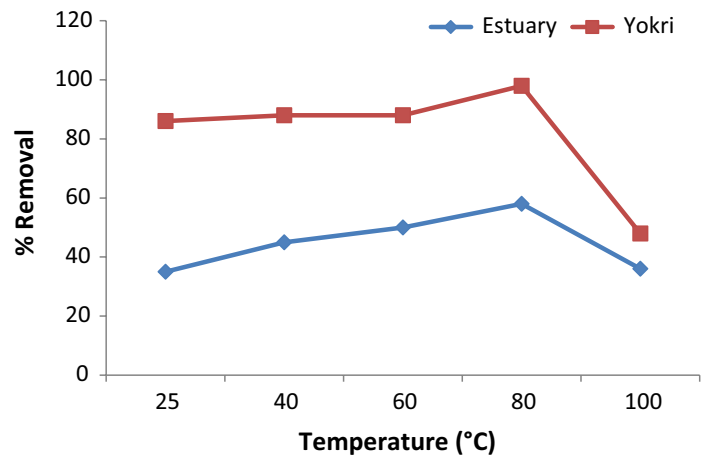

Fig. 7 Effect of temperature on sorption of crude oils onto FBPC

\section{Effect of temperature}

The effect of temperature on sorption may affect the uptake of crude oil on the sorbents (Akpomie et al. 2018). Fig. 7 reveals the effect of temperature on the sorption of Estuary and Yokri crude oils by FBPC. For Estuary crude oil solution, there was an increase in percentage removal from $35 \%$ at $25{ }^{\circ} \mathrm{C}$ to $58 \%$ at $80{ }^{\circ} \mathrm{C}$ where the maximum removal was attained after which the percentage removal decreased to $36 \%$ at $100{ }^{\circ} \mathrm{C}$. In Yokri crude oil, a slight increase in percentage removal was observed from $86 \%$ at $25{ }^{\circ} \mathrm{C}$ to $88 \%$ at $60{ }^{\circ} \mathrm{C}$ after which it increased sharply to $98 \%$ at $80{ }^{\circ} \mathrm{C}$ and then decreased to $48 \%$ at $100{ }^{\circ} \mathrm{C}$. The increment observed may be due to the creation of more active sites on the adsorbent as a result of the dissociation of some of the surface components and the acquisition of more kinetic energy to overcome the energy barrier of the sorption ( $\mathrm{Li}$ et al. 2011). The decrease at $100{ }^{\circ} \mathrm{C}$ is due to an increase in crude oil flow from the sorbent material due to a decrease in viscosity with temperature.

\section{Adsorption isotherm and kinetic analysis}

The sorption isotherm of crude oil on FBPC was analysed by the Temkin, Freundlich, and Langmuir isotherm models (David et al. 2020) while the kinetics was evaluated by the pseudo-first-order, pseudo-second-order and intraparticle diffusion model (Umeh et al. 2020). For brevity, the theory and equations of these models were described in our previous work (Dawodu and Akpomie 2014). The values of the isotherm constants and linear regression coefficient $\mathrm{R}^{2}$ are presented in Table 2. The Langmuir isotherm gave a better fit, for both Estuary (Fig. 8) and Yokri (Fig. 9) crude oils than the Freundlich and Temkin models as revealed by its high $\mathrm{R}^{2}$ values. This implies monolayer sorption of crude oil on a homogenous FBPC surface, suggesting both feldspar and the banana peel biochar were evenly distributed in the composite. The maximum monolayer sorption capacity
Table 2 Equilibrium Isotherm Parameters on Sorption of Crude oils unto FBPC

\begin{tabular}{lrr}
\hline Parameter & \multicolumn{1}{c}{ Estuary } & \multicolumn{1}{c}{ Yokri } \\
\hline Langmuir & & \\
$\mathrm{Q}_{\mathrm{m}}$ & 0.0240 & 0.3562 \\
$\mathrm{~B}$ & -0.1880 & -9.9237 \\
$\mathrm{R}^{2}$ & 0.7782 & 0.9647 \\
Freundlich & & \\
$\mathrm{K}_{\mathrm{f}}$ & 1.1488 & 0.4600 \\
$1 / \mathrm{n}$ & 0.7642 & 0.7445 \\
$\mathrm{~N}$ & 1.3086 & 1.3432 \\
$\mathrm{R}^{2}$ & 0.0022 & 0.7131 \\
Temkin & & \\
$\mathrm{b}_{\mathrm{T}}$ & 1770.07 & -5230.26 \\
$\mathrm{~A}_{\mathrm{T}}$ & 0.2912 & 0.6624 \\
$\mathrm{R}^{2}$ & 0.3167 & 0.4257 \\
\hline
\end{tabular}

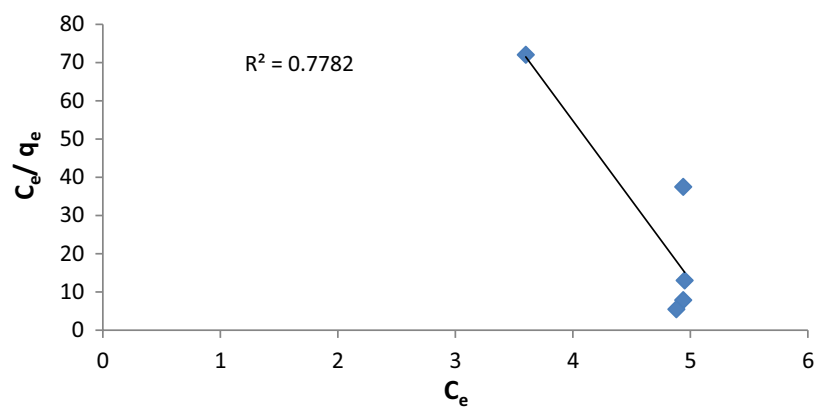

Fig. 8 Langmuir isotherm plot on sorption of Estuary crude oil onto FBPC

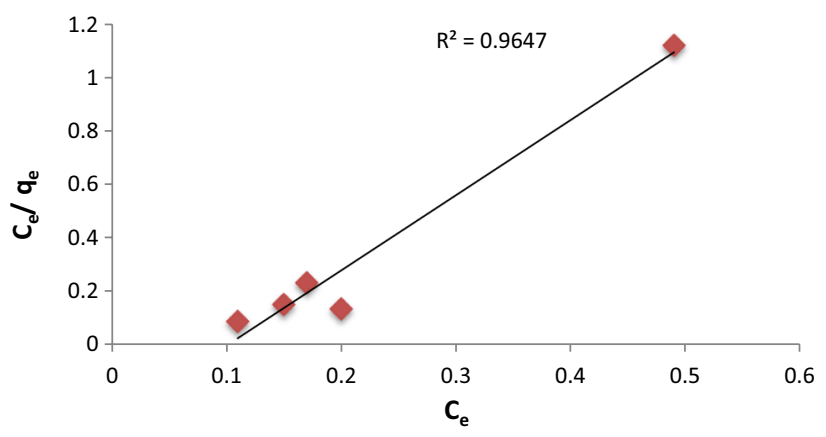

Fig. 9 Langmuir isotherm plot on sorption of Yokri crude oil onto FBPC

indicated a higher uptake of Yokri crude oil $(0.3562 \mathrm{~g} / \mathrm{g})$ compared to Estuary crude oil $(0.0240 \mathrm{mg} / \mathrm{g})$.

The kinetic parameters for the sorption of the crude oils on FBPC are given in Table 3. Among the three kinetic models, the pseudo-second-order model best conformed to the 
Table 3 Kinetic Model Parameters on Sorption of Crude oils unto FBPC

\begin{tabular}{lcr}
\hline Parameter & Estuary & \multicolumn{1}{c}{ Yokri } \\
\hline Pseudo-first-order & & \\
$\mathrm{K}_{1}$ & 0.0046 & 0.0088 \\
$\mathrm{Q}_{1}$ & 0.5698 & 0.4961 \\
$\mathrm{R}^{2}$ & 0.00415 & 0.0797 \\
Pseudo-second-order & & \\
$\mathrm{K}_{2}$ & -6.0456 & -1.0519 \\
$\mathrm{Q}_{2}$ & 0.4531 & 0.8657 \\
$\mathrm{R}^{2}$ & 0.9712 & 0.9988 \\
Intraparticle diffusion & & \\
$\mathrm{K}_{\text {id }}$ & 0.0372 & 0.0682 \\
$\mathrm{C}$ & 0.0923 & 0.2095 \\
$\mathrm{R}^{2}$ & 0.7607 & 0.7124 \\
\hline
\end{tabular}

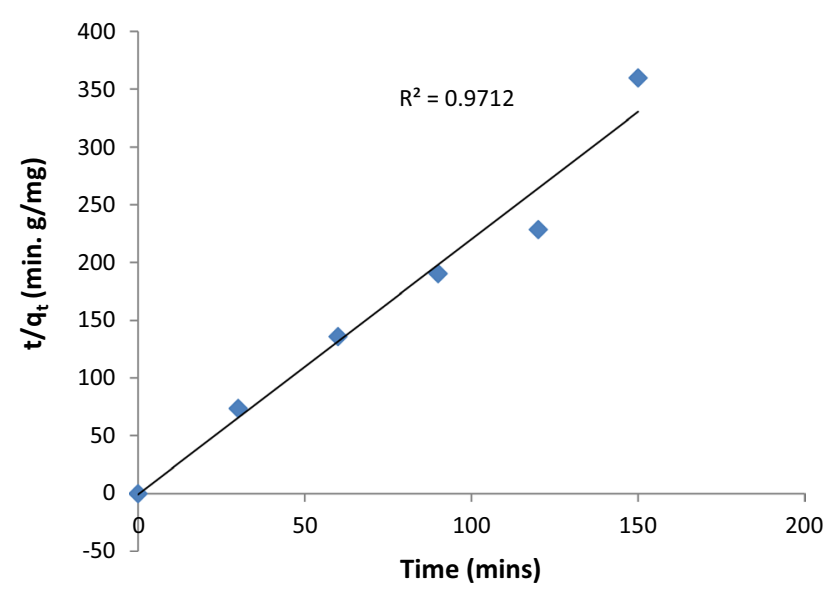

Fig. 10 Pseudo-second-order plot on sorption of Estuary crude oil onto $F B P C$

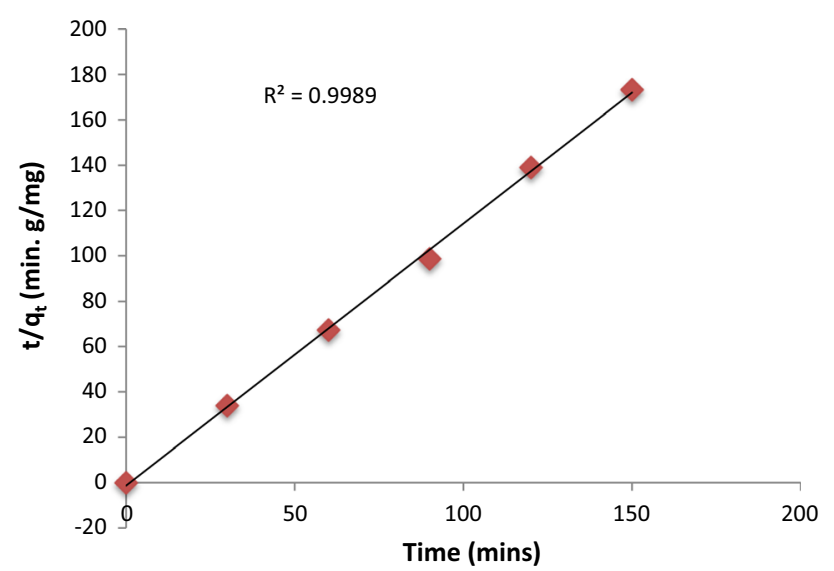

Fig. 11 Pseudo-second-order plot on sorption of Yokri crude oil unto FBPC
Table 4 Thermodynamic parameters for sorption of crude oils onto FBPC

\begin{tabular}{llll}
\hline Parameters & $\Delta \mathrm{G}^{\circ}(\mathrm{KJ} / \mathrm{mol})$ & $\Delta \mathrm{H}^{\circ}(\mathrm{KJ} / \mathrm{mol})$ & $\Delta \mathrm{S}^{\circ}(\mathrm{KJ} / \mathrm{mol} / \mathrm{K})$ \\
\hline Estuary & -0.8304 & -2.2846 & -4.88 \\
Yokri & 5.1088 & 2.5669 & -8.53 \\
\hline
\end{tabular}

experimental data of both Estuary (Fig. 10) and Yokri (Fig. 11) crude oils, due to the higher value of regression coefficient $R^{2}$. This indicated possible electrostatic interaction between FBPC and the crude oil in the solution.

\section{Thermodynamic of crude oil sorption}

Thermodynamic studies enable us to investigate the feasibility, spontaneity, and heat change of sorption. The thermodynamic parameters for crude oil sorption on FBPC such as the Gibbs free energy, $\Delta \mathrm{G}^{0}(\mathrm{KJ} / \mathrm{mol})$, Enthalpy, $\Delta \mathrm{H}^{0}(\mathrm{KJ} / \mathrm{mol})$; and Entropy, $\Delta S^{0}(\mathrm{~J} / \mathrm{mol} / \mathrm{K})$, were calculated using (Dawodu and Akpomie 2014):

$\Delta G^{0}=-R \operatorname{TIn} K$

$\operatorname{InK}=\frac{-\Delta H^{0}}{\mathrm{RT}}+\frac{\Delta S^{0}}{\mathrm{R}}$

where $K$ is the thermodynamic equilibrium constant, $R$ is the ideal gas constant, $T$ is the temperature (K). The thermodynamic constants for the adsorption of Estuary and Yokri crude oils onto FBPC are presented in Table 4. The negative value of $\Delta \mathrm{G}^{0}$ obtained from adsorption of Estuary crude oil by FBPC indicated that the sorption is feasible and spontaneous (Chukwuemeka-okorie et al. 2018). However, the positive value of $\Delta \mathrm{G}^{0}$ obtained for adsorption of Yokri crude oil by FBPC indicated non-spontaneous adsorption (Adebayo et al. 2020). The negative and positive values of $\Delta \mathrm{H}^{0}$, respectively, obtained from adsorption of Estuary and Yokri crude oils by FBPC showed that the sorption process is exothermic and endothermic respectively. For $\Delta S^{o}$, the negative values obtained for the sorption of both Estuary and Yokri crude oils indicated a decrease in randomness. A similar report was obtained (Meitei and Prasad 2013). From the results of $\Delta \mathrm{H}^{\circ}$, it can be inferred that the sorption of Estuary and Yokri crude oils by FBPC are physical due to the low magnitude of $\Delta \mathrm{H}^{0}$, less than $20.9 \mathrm{~kJ} / \mathrm{mol}$ (Akpomie and Conradie 2020). 


\section{Conclusion}

In conclusion, a Feldspar-banana peel biochar composite (FBPC) was used for the sorption of crude oils (Yokri and Estuary) collected from two oil wells in Nigeria. The scanning electron micrograph showed the existence of pores favourable for the sorption of the crude oil from the solution. X-ray diffraction analysis revealed the crystalline phases of the FBPC as feldspar, ilmenite, pyrite, and limestone. Langmuir adsorption isotherm model presented the best fit to the experimental data compared to the Freundlich and Temkin adsorption isotherms, suggesting a monolayer crude oil sorption. Kinetic studies indicated that the pseudo-secondorder was suited to the oil sorption process. Thermodynamics showed that adsorption of the two crude oils occurred through physical sorption due to the low value of enthalpy $\Delta \mathrm{H}^{0}$ obtained. Importantly, the novel prepared composite was found to be efficient for the sorption of the two crude oil from aqueous solution and is recommended for environmental treatment of oil spills.

Financial Disclosure statement The author(s) received no specific funding for this work.

\section{Compliance with ethical standards}

Conflict of Interest The authors declare no conflict of interest.

Open Access This article is licensed under a Creative Commons Attribution 4.0 International License, which permits use, sharing, adaptation, distribution and reproduction in any medium or format, as long as you give appropriate credit to the original author(s) and the source, provide a link to the Creative Commons licence, and indicate if changes were made. The images or other third party material in this article are included in the article's Creative Commons licence, unless indicated otherwise in a credit line to the material. If material is not included in the article's Creative Commons licence and your intended use is not permitted by statutory regulation or exceeds the permitted use, you will need to obtain permission directly from the copyright holder. To view a copy of this licence, visit http://creativecommons.org/licenses/by/4.0/.

\section{References}

Adebayo GB, Adegoke HI, Fauzeeyat S (2020) Adsorption of Cr(VI) ions onto goethite, activated carbon and their composite: kinetic and thermodynamic studies. Appl Water Sci 10:213

Akpomie KG, Conradie J (2020) Advances in application of cotton based adsorbents for heavy metals trapping, surface modifications and future perspectives. Ecotoxicol Environ Saf 201:110825

Akpomie KG, Ezeofor CC, Olikagu CS, Odewole OA, Ezeorah CJ (2018) Abstraction and regeneration potential of temperatureenhanced rice husk montmorillonite combo for oil spill. Environ Sci Pollut Res 25:34711-34719

Akpomie KG, Ezeofor CC, Ani JU, Eze SI, Odo CC, Onoabedje EA (2019) Equilbrium isotherm modeling of crude oil sorption from aqua mixture onto Codiaeum variegatum stem powder. Pet Sci Technol 37(3):329-336

Ali N, El-Harbawi M, Jabal AA, Yin CY (2012) Characteristics and oil sorption effectiveness of Kapok Fibre, sugarcane bagasse and rice husks: Oil removal suitability matrix. Environ Technol 33(4):481-486

Ani JU, Akpomie KG, Okoro UC, Aneke LE, Onukwuli OD, Ujam OT (2020) Potentials of activated carbon produced from biomass, materials for the sequestration of dyes, heavy metals and crude oil components from aqueous environment. Appl Water Sci 10:69

Appenteng MK, Golow AA, Carboo D, Narley VK, Kaka EA, Salifu M, Aidoo F (2013) Physicochemical characterization of the Jubilee crude oil. Appl Chemistry 54:12513-12517

Chukwuemeka-Okorie HO, Ekemezie PN, Akpomie KG, Olikagu CS (2018) Calcined corn cob kaolinite combo as new sorbent for sequestration of toxic metal ions from polluted aqua media and desorption. Frontiers Chem 6:273

David MK, Okoro UC, Akpomie KG, Okey C, Oluwasola HO (2020) Thermal and hydrothermal alkaline modification of kaolin for the adsorptive removal of lead (II) ions from aqueous solution. SN Appl Sci 2:1134

Dawodu FA, Akpomie KG (2014) Simultaneous adsorption of Ni(II) and $\mathrm{Mn}$ (II) ions from aqueous solution unto a Nigerian kaolinite clay. J Mater Res Tech 3(2):129-141

Dawodu FA, Obioha UN, Akpomie KG (2018) Removal of crude oil from aqueous solution by zinc chloride modified Dioscorea rotundata peel carbon: equilibrium, kinetic and intraparticle diffusivity. Pet Coal 60(5):985-994

Eze SI, Akpomie KG, Ezeofor CC, Madubuike NV, Ojo FK (2019) Remediation of oil spill polluted water from Niger Delta Nigeria onto ammonium sulfate modified Dialium guineense seed husk. Pet Sci Technol 37(15):329-336

FEPA (1991) Guidelines and standards for environmental pollution control in Nigeria, Federal Environmental Protection Agency Regulation 1991 on Pollution Abatement in Industries and Facilities Generated Wastes 78(42):38

Ghulam Y, Muhammad IB, Tariq MA, Syed MSRN, Muhammad A, Khizar1 A, Farah NT (2013) Quality and chemistry of crude oils. Journal of Petroleum Technology and Alternative Fuels 4(3): 53-63

Li Y, Xia B, Zhao Q, Liu F, Zhang P, Du Q, Wang D, Li D, Wang Z, Xia Y (2011) Removal of copper ions from aqueous solution by calcium alginate immobilized kaolin. J Environ Sci 23:404-411

Liang S, Guo X, Feng N, Tian Q (2010) Isotherms, kinetics and thermodynamic studies of adsorption of $\mathrm{Cu}(\mathrm{II})$ from aqueous solution by $\mathrm{Mg}^{2+} / \mathrm{K}^{+}$type orange peel adsorbents. J Hazard Mater 174:756-762

Meitei MD, Prasad MNV (2013) Lead(II) and cadmium(II) biosorption on Spirodela polyrhiza (L) schleiden biomass. J Environ Chem Eng 1:200-207

Nwadinigwe CA, Alumona TN (2014) NAASAR procedure for the quantitative assessment of n-alkanes, asphaltenes and resins in crude. J Petrol Explor Prod Tech 5:383-390

Odebunmi EO, Ogunsakin EA, Ilukhor PEP (2002) Characterization of crude oil and petroleum products: (I) Elution liquid chromatographic separation and gas chromatographic analysis of crude oils and petroleum products. Bull Chem Soc Ethiop 16(2):115-132

Ofodile SE, Boisa N, Obunwo CC, Frank OM (2018) Characterisation of oil properties from Niger Delta crude. J Environ Anal Toxicol $8(2): 1-7$

Ohanmu EO, Bako SP (2017) Reproductive capacity of capsicum spp. as affected by crude oil pollution in two weather conditions. Research Journal of Biology 5(4): 8-12

Rodrigues EVA, Silva SRC, Ramao W, Castro EVR, Filgueiras PR (2018) Determination of crude oil physicochemical properties by

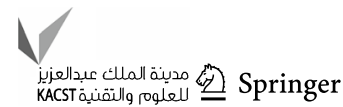


high temperature gas chromatography associated with multivariable calibration. Fuel 220:389-395

Saleh TA, Gupta VK (2012) Column with CNT/magnesium oxide composite for $\mathrm{Pb}(\mathrm{II})$ removal from water. Environ Sci Pollut Res 19:1224-1228

Sathasivam K, Mas Haris MRH (2010) Adsorption kinetics and capacity of fatty acid-modified banana trunk fibers for oil in water. Water Air Soil Poll 213:413-423

Singh R, Gautam N, Mishra A, Gupta R (2011) Heavy metals and living systems: an overview. Ind J Pharm 43:246-253

Topsoe H, Bjerne CS, Massoth FE (1996) Hydro-treating Catalysis: Science and Technology. J Catal Sci Technol 11:1-310

Umeh C, Asegbeloyin JN, Akpomie KG, Oyeka EE, Ochonogor AE (2020) Adsorption properties of tropical soils from Awka North Anambra Nigeria for lead and cadmium ions from aqueous media. Chem Afr 3:199-210
UNEP/GRID (2011) Historical trends in carbon dioxide concentrations and temperature, on a geological and recent time scale. In-Arendal Maps and Graphics Library

Winsley P (2007) Biochar and bioenergy production for climate change mitigation. New Zealand Sci Rev 64(5):5

Yasir AA (2015) Standard Test for Ash from Petroleum Products. Department of Petroleum Engineering, Faculty of Engineering, University of Zakho, Iraq, D482

Publisher's Note Springer Nature remains neutral with regard to jurisdictional claims in published maps and institutional affiliations. 